\title{
PENGARUH KUALITAS PELAYANAN KEFARMASIAN TERHADAP TINGKAT KEPUASAN PASIEN DI EMPAT APOTEK KOTA TANGERANG SELATAN
}

Melizsa ${ }^{*}$, Renato Putra Herwina, Magdalena Niken

STIKes Kharisma Persada, J1. Pajajaran No 1, Tangerang Selatan 15417, Indonesia

\begin{tabular}{|c|c|}
\hline ARTICLE INFORMATION & $A B S T R A C T$ \\
\hline $\begin{array}{l}\text { *Corresponding Author } \\
\text { Melizsa } \\
\text { E-mail: melizsa@masda.ac.id }\end{array}$ & $\begin{array}{l}\text { There has been a shift in the orientation of } \\
\text { pharmaceutical services from only drug management to } \\
\text { comprehensive patient care (Pharmaceutical Care). Some } \\
\text { factors that influence the level of patient satisfaction are the }\end{array}$ \\
\hline $\begin{aligned} & \text { Keywords: } \\
& \text { - } \text { Service; } \\
& \text { - } \text { Quality; } \\
& \text { - } \text { Patient Satisfaction }\end{aligned}$ & $\begin{array}{l}\text { to determine the Effect of Pharmaceutical Service Quality on } \\
\text { Patient Satisfaction Level in Four Pharmacy City of South } \\
\text { Tangerang. This research is a type of quantitative analytic } \\
\text { research with cross sectional method. This study uses an } \\
\text { accidental sampling method by distributing questionnaires to } \\
100 \text { respondents in four South Tangerang city pharmacies. The } \\
\text { results showed that the quality of pharmaceutical services has a } \\
\text { strong influence on the level of patient satisfaction that has a } \\
\text { Pearson correlation of } 0.714 \text {. The assessment category for the } \\
\text { service quality variable produced a pretty good answer (65\%) } \\
\text { and quite satisfied (75\%) forpatient satisfaction. The quality of } \\
\text { services provided by the four pharmacies is good, but it must be } \\
\text { continuously improved so that there is no decrease in patient } \\
\text { satisfaction in the future }\end{array}$ \\
\hline $\begin{array}{l}\text { Kata Kunci: } \\
\text { - Kualitas } \\
\text { - Pelayanan Kefarmasian; } \\
\text { - } \quad \text { Tingkat Kepuasan Pasien }\end{array}$ & $\begin{array}{l}\text { Telah terjadi pergeseran orientasi pelayanan } \\
\text { kefarmasian dari hanya pengelolaan obat menjadi pelayanan ke } \\
\text { pasien yang komprehensif (Pharmaceutical Care). Kualitas } \\
\text { pelayanan kefarmasian mempengaruhi tingkat kepuasan pasien. } \\
\text { Tujuan penelitian ini adalah untuk mengetahui Pengaruh } \\
\text { Kualitas Pelayanan Kefarmasian terhadap Tingkat Kepuasan } \\
\text { Pasien di Empat Apotek Kota Tangerang Selatan. Penelitian ini } \\
\text { adalah jenis penelitian analitik kuantitatif dengan metode cross } \\
\text { sectional. Penelitian ini mengunakan metode pengambilan } \\
\text { sampel accidental sampling dengan menyebarkan kuesioner } \\
\text { kepada } 100 \text { responden di empat apotek kota Tangerang Selatan. } \\
\text { Hasil penelitian menunjukkan jika Kualitas pelayanan } \\
\text { kefarmasian memiliki pengaruh yang kuat dengan tingkat } \\
\text { kepuasan pasien yang memiliki nilai pearson korelasi 0,714. } \\
\text { Kategori penilaian untuk variabel kualitas pelayanan } \\
\text { menghasilkan jawaban cukup baik (65\%), cukup puas (75\%) } \\
\text { pada kepuasan pasien, Kualitas pelayanan yang diberikan oleh } \\
\text { ke empat apotek sudah baik, tetapi harus terus ditingkatkan agar } \\
\text { tidak terjadi penurunan tingkat kepuasan pasien di masa } \\
\text { mendatang. }\end{array}$ \\
\hline
\end{tabular}




\section{PENDAHULUAN}

Kesehatan adalah faktor penting yang sangat diperlukan dalam kehidupan manusia, sehingga saat ini banyak dijumpai sarana farmasi berupa Apotek. Arti dari pelayanan kefarmasian adalah suatu pelayanan yang diberikan secara langsung dan bertanggung jawab kepada konsumen yang berkaitan dengan pemberian obat-obatan dan alat kesehatan dengan tujuan mencegah penyakit, mengobati penyakit dan meningkatkan mutu kehidupan. Saat ini masyarakat sangat membutuhkan pelayanan kefarmasian yang baik untuk mendapatkan informasi tentang berbagai macam sediaan farmasi.

Dewasa ini pelayanan kefarmasian di Apotek dituntut untuk merubah orientasinya dari product atau drug oriented menjadi patient oriented, (Ihsan et al. 2014). Tetapi dalam praktiknya masih cukup banyak apotek yang pelayanannya lebih berorientasi kepada produk dan berfungsi sebagai ritel farmasi biasa, (Sampurno, 2011). Mengelola bisnis apotek tidak dapat disamakan dengan bisnis lainnya, karena bisnis apotek adalah bisnis yang wajib mengikuti regulasi dan sarat dengan etika profesi. Regulasi dan etika yang mengatur bisnis apotek berfungsi untuk meminimalisir risiko dari obat-obatan yang dijual kepada masyarakat.
Menurut Simamora dalam Wulandari (2017), ada dua faktor yang mempengaruhi kualitas pelayanan yaitu expected service dan perceived service. Apabila pelayanan yang didapatkan dan dirasakan sesuai dengan yang diharapkan pasien, maka kualitas pelayanan dipersepsikan baik dan memuaskan. Jika pelayanan yang diterima melampaui harapan pasien, maka kualitas pelayanan dipersepsikan sebagai kualitas pelayanan ideal. Sebaliknya bila pelayanan yang diterima lebih rendah daripada harapan pasien, maka kualitas pelayanan dipersepsikan buruk, dengan demikian baik atau buruknya kualitas pelayanan sangat bergantung pada kemampuan apotek yang menyediakan layanan dalam memenuhi harapan pasien. Suatu pelayanan yang berkualitas menurut Baroroh (2014) adalah yang mampu menyesuaikan harapan konsumen dengan konsisten. tinggi rendahnya sebuah kualitas pelayananan dapat diukur dari bagaimana konsumen merasakan pelayanan yang diberikan apakah sesuai dengan yang mereka harapkan, (Pratiwi et al. 2013).

Kepuasan adalah hal terpenting dalam suatu pekerjaan yang berhubungan dengan pelayanan kesehatan. Kepuasan pasien menjadi sebuah tolak ukur dari kualitas pelayanan kesehatan yang diberikan oleh tenaga teknis kefarmasian 
di apotek, (Susi et al. 2018). Apabila kepuasan pasien yang dihasilkan baik, maka pelayanan yang diberikan oleh apotek sudah cukup baik. namun jika pasien merasa tidak puas dengan pelayanan yang diberikan, berarti perlu dilakukan evaluasi khusus tentang kualitas pelayanan kefarmasian yang dilakukan oleh apotek tertentu.

Pelayanan bermutu adalah memberikan pelayanan kepada pasien yang didasarkan pada standart kualitas untuk memenuhi kebutuhan dan keinginan mereka, sehingga dapat memperoleh kepuasan sesuai dengan apa yang diharapkan dan dapat meningkatkan loyalitas pasien terhadap apotek (Mabow dalam Wulandari, 2017). Kualitas pelayanan kefarmasian dan kepuasan pasien menjadi indikator keberhasilan penyelenggaraan pelayanan di apotek. Pada dasarnya kualitas pelayanan yang baik tidak hanya dijadikan target yang harus dicapai, tetapi juga harus terus dipertahankan mengingat adanya perubahan kebutuhan, harapan dan keinginan pasien. Apotek sebagai sarana pelayanan kesehatan diharapkan mampu memberikan kualitas pelayanan kefarmasian yang baik untuk meningkatkan kepuasan pasien. Loyalitas pasien terbentuk apabila pasien merasa puas dengan kualitas pelayanan yang diberikan oleh pihak apotek.
Menurut penelitian yang dilakukan oleh Wulandari pada tahun 2017, prosentase yang menunjukkan kualitas pelayanan dengan kategori baik sebesar $41,3 \%$ dan kategori tidak baik sebesar $58,7 \%$. Untuk tingkat kepuasan pasien, angka prosentase pasien yang merasa puas dengan kualitas pelayanan di rumah sakit Dungus Madiun sebesar $42,4 \%$ dan tidak puas sebesar $57,6 \%$.

Riset yang dilakukan Monika, dkk, pada tahun 2015 sudah mampu menegaskan jika ada hubungan antara pelayanan kefarmasian dengan kepuasan pelanggan. Penelitian yang dilakukan oleh Putri, 2017 menunjukkan bahwa secara keseluruhan pelanggan merasa puas dengan pelayanan farmasi instalasi farmasi RS X dengan tingkat kesesuaian kinerja dan harapan $>75 \%$.

Penelitian yang dilakukan oleh Habel Roy Sulo, 2019 berdasarkan hasil uji analisis gap, pelanggan rawat jalan belum merasa puas atas kualitas pelayanan yang diberikan oleh Instalasi Farmasi Rumah Sakit X Kota Surakarta.

Penelitian yang dilakukan oleh Putu Eka Arimbawa, 2014 bahwa kecepatan pelayanan berhubungan secara signifikan terhadap kepuasan pasien. Penelitian yang dilakukan oleh Manurung, 2010 mengatakan bahwa keramahan petugas memiliki hubungan positif dengan minat kembali menebus 
resep obat. Hal ini didukung oleh penelitian yang dilakukan Saragih, dkk, 2010 yang menyatakan terdapat pengaruh antara keramahan petugas terhadap loyalitas pelanggan. Pelanggan yang diperlakukan kurang baik cenderung untuk mengabaikan saran dan nasehat petugas, (Yunevy dan Haksamana, 2013).

Pertumbuhan apotek di kota Tangerang Selatan dalam beberapa tahun terakhir sudah sangat pesat. Dari data yang ditulis oleh Dinkes kota Tangerang Selatan tahun 2015 disebutkan bahwa jumlah apotek di kota ini sudah mencapai 347 apotek. Dari total 347 Apotek yang berada di kota Tangerang Selatan, terdapat 79 Apotek di kecamatan Serpong, 48 Apotek di kecamatan Serpong Utara, 9 Apotek di kecamatan Setu, 6 Apotek di kecamatan Pamulang, 32 Apotek di kecamatan Ciputat, 40 Apotek di kecamatan Ciputat Timur, dan 83 Apotek di kecamatan Pondok Aren.

Pada tanggal 02 Maret 2020 pukul 10.00 - 12.00 WIB peneliti melakukan survei pendahuluan di apotek B'WIN. Peneliti mewawancarai Apoteker pengelola apotek tentang keluhan pasien yang berkaitan dengan kualitas pelayanan dan kepuasan pasien di Apotek B'WIN. Permasalahan yang ada di apotek B'WIN adalah kurang nyamannya ruang tunggu pasien dan tidak tersedianya toilet untuk pasien. Tanggal 03 Maret 2020 pukul
14.00 - $16.00 \mathrm{WIB}$, peneliti melakukan survei pendahuluan di apotek K-24 Pondok Cabe. Hasil wawancara dengan pasien yang membeli obat di apotek K-24 didapatkan keluhan tentang kurangnya kemampuan tenaga teknis kefarmasian dalam membaca resep. Selanjutnya pada tanggal 05 Maret 2020 pukul 09.00 10.00 WIB peneliti melakukan survei pendahuluan dengan melakukan wawancara kepada Apoteker pengelola apotek Karunia Sehat. Pada wawancara tersebut Apoteker menjelaskan kepada peneliti bahwa ada beberapa pasien yang mengeluh tentang keramahan pegawai apotek dalam melakukan pelayanan saat beliau tidak berada di tempat. Survei pendahuluan terakhir yang peneliti lakukan adalah di apotek Maleo. Survei dilakukan pada tanggal 07 Maret 2020 pukul 15.30 - 17.00 WIB, peneliti melakukan wawancara dengan pasien yang membeli obat ke apotek Maleo. Dari hasil wawancara didapatkan keluhan tentang tenaga teknis kefarmasian yang tidak memberikan informasi dosis penggunaan obat jika pasien tidak bertanya.

Dari hasil survei pendahuluan tersebut, peneliti ingin melakukan penelitian di empat apotek kota Tangerang Selatan yaitu; apotek B'WIN, apotek Karunia Sehat, apotek K-24 Pondok Cabe dan apotek Maleo dengan 
judul penelitian "Pengaruh Kualitas

Pelayanan Kefarmasian Terhadap Tingkat

\section{METODE}

Penelitian ini dilakukan menggunakan survei analitik dengan desain cross sectional, yaitu metode penelitian yang dilakukan untuk mempelajari dinamika korelasi dengan cara pendekatan, observasi atau
Kepuasan Pasien di Empat Apotek Kota Tangerang Selatan Tahun 2020”.

pengumpulan data sekaligus pada saat itu juga, (Notoatmodjo, 2018).

Rancangan penelitian ini digunakan untuk menggambarkan kualitas pelayanan kefarmasian terhadap tingkat kepuasan pasien di empat Apotek kota Tangerang Selatan Tahun 2020.

\section{HASIL}

Karakteristik Responden

a. Umur

Tabel 1 Karakteristik Responden Berdasarkan Umur

\begin{tabular}{llll}
\hline \multirow{2}{*}{ No } & \multirow{2}{*}{ Umur } & \multicolumn{2}{c}{ Jumlah } \\
\cline { 3 - 4 } & $<17$ & $\mathrm{~N}$ & $\%$ \\
\hline 1 & $17-25$ & 11 & 11 \\
2 & $26-35$ & 44 & 18 \\
3 & $>35$ & 27 & 44 \\
4 & Total & 100 & 27 \\
\hline & &
\end{tabular}

Sumber : Data primer, 2020.

Berdasarkan Tabel 1 dapat

diketahui bahwa dari hasil karakteristik responden hasil tertinggi menunjukkan proporsi pada umur 26-35 tahun dengan jumlah responden 44 orang dengan presentase $44 \%$ dan hasil yang rendah berada pada proporsi umur $<17$ tahun terdapat 11 responden dengan presentase $11 \%$.

b. Jenis Kelamin

Tabel 2 Karakteristik Responden Berdasarkan Jenis Kelamin

\begin{tabular}{llll}
\hline \multirow{2}{*}{ No } & \multirow{2}{*}{ Jenis Kelamin } & \multicolumn{2}{c}{ Jumlah } \\
\cline { 3 - 4 } & & $\mathrm{N}$ & $\%$ \\
\hline 1 & Laki-laki & 56 & 56 \\
2 & Perempuan & 44 & 44 \\
\hline & Total & 100 & 100 \\
\hline
\end{tabular}

Sumber : Data primer, 2020. 
Berdasarkan Tabel 2 dapat

diketahui bahwa dari hasil

karakteristik responden ada

perbedaan hasil antara jenis kelamin

laki-laki dan perempuan. Proporsi untuk jenis kelamin laki-laki terdapat 56 responden dengan presentase $56 \%$ dan jenis kelamin perempuan terdapat 44 responden dengan presentase $44 \%$.

c. Pekerjaan

Tabel 3 Karakteristik Responden Berdasarkan Pekerjaan

\begin{tabular}{llll}
\hline \multirow{2}{*}{ No } & \multirow{2}{*}{ Pekerjaan } & \multicolumn{2}{c}{ Jumlah } \\
\cline { 3 - 4 } & & $\mathrm{N}$ & $\%$ \\
\hline 1 & Pelajar & 17 & 17 \\
2 & Wiraswasta & 14 & 14 \\
3 & PNS & 12 & 12 \\
4 & Pegawai Swasta & 36 & 36 \\
5 & Ibu Rumah Tangga & 21 & 21 \\
\hline & Total & 100 & 100 \\
\hline
\end{tabular}

Sumber : Data primer, 2020.

Berdasarkan Tabel 3 dapat diketahui bahwa dari hasil karakteristik responden, proporsi tertinggi adalah responden yang bekerja sebagai pegawai swasta yaitu sebesar 36 orang dengan presentase $36 \%$. Proporsi terendah berasal dari responden yang bekerja sebagai PNS, yaitu sebanyak 12 orang dengan presentase $12 \%$.

d. Pendidikan Terakhir

Tabel 4 Karakteristik Responden Berdasarkan Pendidikan

\begin{tabular}{llll}
\hline \multirow{2nyy}{*}{ Tingkat Pendidikan } & \multicolumn{2}{c}{ Jumlah } \\
\cline { 3 - 4 } & & $\mathrm{N}$ & $\%$ \\
\hline 1 & SD/Sederajat & 1 & 1 \\
2 & SMP/Sederajat & 4 & 4 \\
3 & SMA/Sederajat & 46 & 46 \\
4 & Diploma & 23 & 23 \\
5 & Sarjana & 26 & 25 \\
\hline & Total & 100 & 100 \\
\hline
\end{tabular}

Sumber : Data primer, 2020.

Berdasarkan Tabel 4 dapat diketahui bahwa dari hasil karakteristik responden, proporsi tertinggi adalah responden yang memiliki tingkat pendidikan SMA yaitu sebesar 46 orang dengan presentase $46 \%$. Proporsi terendah berasal dari responden yang berpendidikan terakhir SD, yaitu sebanyak 1 orang dengan presentase 
$1 \%$.

2. Hasil Pengkategorian Jawaban Responden

a. Variabel Kualitas Pelayanan

1) Kehandalan (Reliability)

Tabel 5 Distribusi Frekuensi Kehandalan

\begin{tabular}{lll}
\hline Kategori & Jumlah & Presentase \\
\hline Kurang Baik & 9 & $9 \%$ \\
Cukup Baik & 74 & $74 \%$ \\
Baik & 17 & $17 \%$ \\
\hline
\end{tabular}

Sumber : Data primer, 2020

Berdasarkan hasil

perhitungan di atas menunjukan

bahwa dari 100 responden yang

menjawab kurang baik

sebanyak 17 responden. Hal ini

sebanyak 9 responden, cukup

menunjukan jika mayoritas

responden merasa kualitas

baik 74 responden, dan baik

pelayanan kefarmasian dengan

indikator kehandalan di empat apotek sudah cukup baik.

2) Ketanggapan (Responsiveness)

Tabel 6 Distribusi Frekuensi Ketanggapan

\begin{tabular}{lll}
\hline Kategori & Jumlah & Presentase \\
\hline Kurang Baik & 9 & $9 \%$ \\
Cukup Baik & 78 & $78 \%$ \\
Baik & 13 & $13 \%$ \\
\hline
\end{tabular}

Sumber : Data primer, 2020

Berdasarkan hasil

perhitungan di atas menunjukan

bahwa dari 100 orang

responden yang menjawab

kurang baik sebanyak 9

responden, cukup baik 78

responden, dan baik sebanyak

3) Empati (Emphaty)
13 responden. Hal ini menunjukan jika mayoritas responden merasa kualitas pelayanan kefarmasian dengan indikator ketanggapan di empat apotek sudah cukup baik.

Tabel 7 Distribusi Frekuensi Empati

\begin{tabular}{lll}
\hline Kategori & Jumlah & Presentase \\
\hline Kurang Baik & 7 & $7 \%$ \\
Cukup Baik & 82 & $82 \%$ \\
Baik & 11 & $11 \%$ \\
\hline
\end{tabular}

Sumber : Data, 2020 
Berdasarkan hasil

perhitungan di atas menunjukan

bahwa dari 100 responden yang

menjawab kurang baik

sebanyak 7 responden, cukup

baik 82 responden, dan baik sebanyak 11 responden. Hal ini menunjukan jika mayoritas responden merasa kualitas pelayanan kefarmasian dengan indikator empati di empat apotek sudah cukup baik.

4) Jaminan (Assurance)

Tabel 8 Distribusi Frekuensi Jaminan

\begin{tabular}{llc}
\hline Kategori & Jumlah & Presentase \\
\hline Kurang Baik & 11 & $11 \%$ \\
Cukup Baik & 71 & $71 \%$ \\
Baik & 18 & $18 \%$ \\
\hline
\end{tabular}

Sumber : Data primer, 2020

Berdasarkan hasil

perhitungan di atas menunjukan

bahwa dari 100 responden yang

menjawab kurang baik

sebanyak 7 responden, cukup

baik 71 responden, dan baik sebanyak 18 responden. Hal ini menunjukan jika mayoritas responden merasa kualitas pelayanan kefarmasian dengan indikator jaminan di empat apotek sudah cukup baik.

5) Bukti Nyata (Tangible)

Tabel 9 Distribusi Frekuensi Bukti Fisik

\begin{tabular}{llc}
\hline Kategori & Jumlah & Presentase \\
\hline Kurang Baik & 14 & $14 \%$ \\
Cukup Baik & 82 & $82 \%$ \\
Baik & 4 & $14 \%$ \\
\hline Sumber : Data primer, 2020
\end{tabular}

Berdasarkan hasil

perhitungan di atas menunjukan

bahwa dari 100 responden yang

menjawab kurang baik

sebanyak 14 responden, cukup

baik 82 responden, dan baik sebanyak 4 responden. Hal ini menunjukan jika mayoritas responden merasa kualitas pelayanan kefarmasian dengan indikator bukti nyata di empat apotek sudah cukup baik.

b. Variabel Tingkat kepuasan

1) Kecepatan Pelayanan

Tabel 10 Distribusi Frekuensi Kecepatan Pelayanan

\begin{tabular}{lll}
\hline Kategori & Jumlah & Presentase \\
\hline Tidak Baik & 6 & $6 \%$ \\
Cukup Baik & 79 & $79 \%$ \\
Baik & 15 & $25 \%$ \\
\hline
\end{tabular}

Sumber : Data primer, 2020. 
Berdasarkan hasil

perhitungan di atas menunjukan

bahwa dari 100 orang

responden yang menjawab

kurang baik sebanyak 6

responden, cukup baik 79

responden, dan baik sebanyak
15 responden. Hal ini menunjukan jika mayoritas responden merasa cukup puas dengan kecepatan pelayanan yang diberikan di empat apotek kota Tangerang Selatan.

2) Keramahan Karyawan

\begin{tabular}{llc}
\multicolumn{3}{l}{ Tabel 11 Distribusi Frekuensi Keramahan Karyawan } \\
\hline Kategori & Jumlah & Presentase \\
\hline Tidak Baik & 10 & $10 \%$ \\
Cukup Baik & 80 & $80 \%$ \\
Baik & 10 & $10 \%$ \\
\hline
\end{tabular}

Sumber : Data primer, 2020.

Berdasarkan hasil

perhitungan di atas menunjukan

bahwa dari 100 orang

responden yang menjawab

kurang baik sebanyak 10

responden, cukup baik 80

responden, dan baik sebanyak
10 responden. Hal ini menunjukan jika mayoritas responden merasa cukup puas dengan keramahan karyawan yang melakukan pelayanan di empat apotek kota Tangerang Selatan

3) Pengetahuan Karyawan

Tabel 12 Distribusi Frekuensi Pengetahuan Karyawan

\begin{tabular}{llc}
\hline Kategori & Jumlah & Presentase \\
\hline Tidak Baik & 10 & $10 \%$ \\
Cukup Baik & 75 & $75 \%$ \\
Baik & 15 & $15 \%$ \\
\hline
\end{tabular}

Sumber : Data primer , 2020.

Berdasarkan hasil

perhitungan di atas menunjukan bahwa dari 100 orang responden yang menjawab kurang baik sebanyak 10 responden, cukup baik 75 responden, dan baik sebanyak
15 responden. Hal ini menunjukan jika mayoritas responden merasa cukup puas dengan pengetahuan yang dimiliki karyawan tentang obatobatan yang dijual di empat apotek kota Tangerang Selatan. 
4) Tampilan Fasilitas

Tabel 13 Distribusi Frekuensi Tampilan Fasilitas

\begin{tabular}{lll}
\hline Kategori & Jumlah & Presentase \\
\hline Tidak Baik & 11 & $11 \%$ \\
Cukup Baik & 80 & $80 \%$ \\
Baik & 9 & $9 \%$ \\
\hline
\end{tabular}

Berdasarkan hasil

perhitungan di atas menunjukan

bahwa dari 100 orang

responden yang menjawab

kurang baik sebanyak 11

responden, cukup baik 80 responden. Hal ini menunjukan

jika mayoritas responden merasa cukup puas dengan tampilan fasilitas yang ada di empat apotek kota Tangerang Selatan.

responden, dan baik sebanyak 9

5) Pelayanan Yang Tersedia

Tabel 14 Distribusi Frekuensi Pelayanan Yang Tersedia

\begin{tabular}{llc}
\hline Kategori & Jumlah & Presentase \\
\hline Tidak Baik & 6 & $11 \%$ \\
Cukup Baik & 84 & $84 \%$ \\
Baik & 10 & $10 \%$ \\
\hline
\end{tabular}

Sumber : Data primer, 2020.

Berdasarkan hasil

perhitungan di atas menunjukan bahwa dari 100 orang responden yang menjawab kurang baik sebanyak 6 responden, cukup baik 84 responden, dan baik sebanyak 10 responden. Hal ini menunjukan jika mayoritas responden merasa cukup puas dengan pelayanan yang tersedia di empat apotek kota Tangerang Selatan.
3. Hasil uji statistik, pengaruh kualitas pelayanan kefarmasian terhadap tingkat kepuasan pasien di empat apotek kota Tangerang selatan

Nilai signifikansi untuk hubungan kualitas dengan pelayanan adalah $0,00<0,05$ maka dapat diartikan bahwa terdapat pengaruh antara kualitas pelayanan dengan tingkat kepuasan. Nilai pearson korelasi pada tabel diatas adalah 0,714, yang berarti tingkat hubungan antara kualitas pelayanan dengan tingkat kepuasan adalah kuat. 


\section{DISKUSI}

Kepuasan pelanggan adalah hasil evaluasi dari pasien yang mendapatkan pelayanan dan produk dengan kualitas baik sesuai dengan apa yang diharapkan dan mereka akan menggunakan barang atau jasa tersebut kembali. Hal ini terbukti benar karena seseorang dapat di katakan puas jika apa yang didapatkan lebih besar dari apa yang diharapkan.

Berdasarkan hasil statistik pada uji korelasi dimana hasil menunjukkan nilai person korelasi 0,714 yang artinya adanya hubungan yang kuat antara kualitas 2017. Hal tersebut juga sejalan menurut Hidayat dalam Wulandari (2017:90) Pengaruh kualitas pelayanan kefarmasian terhadap tingkat kepuasan pasien memiliki dua hal pokok yang saling berkaitan erat, yaitu harapan pelanggan terhadap kualitas pelayanan dan kualitas yang dirasakan. Hubungan kualitas pelayanan dan tingkat kepuasan pasien tidak terlepas dari kreativitas pelayanan yang ditawarkan. Untuk mewujudkan suatu pelayanan berkualitas yang mampu memberikan rasa puas kepada pasien,maka pegawai apotek harus mampu memahami persepsi dan harapan pasien, (Hidayat dalam Wulandari, 2017: 90).

Berdasarkan hasil penelitian dari variabel kualitas pelayanan, semua pelayanan dengan tingkat kepuasan, hal ini sejalan dengan penelitian Wulandari (2017) yang berjudul "Pengaruh Kualitas Pelayanan Terhadap Kepuasan Pasien di Instalasi Farmasi Rumah Sakit Paru Dungus Madiun Tahun 2017" dimana Berdasarkan hasil analisis bivariat uji chisquare didapatkan nilai sig (p) 0,048 yang berarti < 0,05 maka $\mathrm{H} 0$ ditolak dan $\mathrm{H} 1$ diterima, artinya terdapat pengaruh yang signifikan antara kualitas pelayanan terhadap kepuasan pasien di Instalasi Rumah Sakit Paru Dungus Madiun tahun dimensi menunjukan hasil yang cukup baik dari ke empat apotek, begitupun dengan variabel tingkat kepuasan menunjukan hasil yang cukup baik dari 100 responden yang peneliti ambil sebagai sampel di empat apotek. Hal ini dapat disimpulkan jika memberikan kualitas pelayanan di apotek maka menghasilkan kepuasan pelanggan yang sebanding.

\section{SIMPULAN}

Dilihat pada uji korelasi product moment dengan nilai derajat hubungan 0,714 yang berarti terdapat pengaruh kuat antara kualitas pelayanan kefarmasian terhadap tingkat kepuasan pasien di empat apotek kota Tangerang Selatan. Dari uji hipotesis simultan (uji t) dan uji hipotesis parsial 
(uji F) juga didapatkan hasil signifikan yang menjelaskan bahwa terdapat pengaruh antara kualitas pelayanan kefarmasian dengan tingkat kepuasan pasien di empat apotek kota Tangerang Selatan.

\section{DAFTAR PUSTAKA}

Anief. (2014). Manajemen Farmasi. Yogyakarta: Gadjah Mada University Press.

Arief. (2018). Pemasaran Jasa dan Kualitas Pelayanan. Jakarta: Bayumedia.

Baroroh, F. (2014). Evaluasi Kepuasan Konsumen Terhadap Pelayanan Kefarmasian di Apotek Kota Yogyakarta. Skripsi, Fakultas Farmasi Ahmad Dahlan, Yogyakarta.

Daulay, M. (2015). Tingkat Kepuasan Pasien Rawat Jalan Peserta BPJS Kesehatan Terhadap Pelayanan Kefarmasian di Dua Puskesmas di Kota Medan Bulan Agustus 2015. Skripsi, Fakultas Farmasi, Universitas Sumatera Utara, Medan.

Dinkes Kota Tangerang Selatan. (2016). Renstra Dinas Kesehatan Kota Tangerang Selatan Tahun 20162021. Tangerang Selatan: Dinkes Kota Tangerang Selatan.
Ghozali, I. (2018). Aplikasi Analisis Multivariate dengan Program IBM SPSS 25. Semarang: Badan Penerbit Universitas Diponegoro.

Habel Roy Sulo et al. (2019). Analisis Pengaruh Kualitas Pelayanan Terhadap Kepuasan Pasien Rawat Jalan Di Instalasi Farmasi Rumah Sakit X Kota Surakarta. Jurnal Ilmiah Manuntung, 81-90.

Hardiyansyah. (2018). Kualitas Pelayanan Publik. Yogyakarta: Gava Media.

Ihsan S, R. R. (2014). Evaluasi Mutu Pelayanan Di Apotek Komunitas Kota Kendari BerdasarkanStandar Pelayanan Kefarmasian. Jurnal Farmasi dab Ilmu Kefarmasian Indonesia 1, 30-35.

Kottler, K. (2009). Manajemen Pemasaran Edisi 13. Jakarta: Erlangga.

Kurniati. (2013). Kepuasan Pasien Rawat Inap Lontara Kelas III Terhadap Pelayanan Kesehatan Di Rumah Sakit Wahidin Sudirohusodo Makassar. Skripsi Kurniati.

Menteri Kesehatan Republik Indonesia. (2014). Peraturan Menteri Kesehatan Republik Indonesia No.35 Tahun 2014 Tentang Standar Pelayanan Kefarmasian di Apotek. Jakarta: MENKES RI. 
Menteri Kesehatan Republik Indonesia. (2017). Peraturan Menteri Kesehatan Republik Indonesia No.9 Tahun 2017 Tentang Apotek. Jakarta: Menteri Kesehatan Republik Indonesia.

Monika et al. (2015). Hubungan Antara Mutu Pelayanan Kefarmasian dengan Kepuasan Pasien Rawat Jalan di Puskesmas Teling Atas Kota Manado. Junal Ilmiah Farmasi Vollume 4, Universitas Sam Ratulangi, Manado, 261-269.

Notoatmodjo. (2012). Metodologi

Penelitian Kesehatan. Jakarta: Rineka Cipta.

Putu Eka Arimbawa. (2014). Hubungan

Pelayanan Kefarmasian Dengan

Kepuasan Pasien Menggunakan

Jasa Apotek Di Kota Denpasar.

Publich Health and Preventive Medicine Archive.

Republik Indonesia. (2014). Peraturan Menteri Kesehatan Republik Indonesia Nomor 35 Tentang Standar Pelayanan Kefarmasian Di Apotek. Jakarta: Departemen Kesehatan.

Republik Indonesia. (2014b). Peraturasn Menteri Kesehatan Republik Indonesia Nomor 35 Tahun 2014 tentang Standar Pelayanan Kefarmasian di Apotek. Jakarta.
Richard F. Gerson. (2018). Mengukur Kepuasan Pelanggan. Jakarta: PPM.

Sampurno. (2011). Manajemen Pemasaran Farmasi. Yogyakarta: Gajah Mada University Press.

Sugiyono. (2018). Metodologi Penelitian Kuantitatif Kualitatif dan $R \& D$. Yogyakarta: Alfabeta.

Sukamto, H. (2017). Evaluasi kepuasan pasien terhadap pelayanan kefarmasian di apotek rawat jalan RSUP DR. Wahidin Sudirohusodo kota Makassar. Skripsi Herlinda.

Tjiptono Fandy, A. (2019). Kepuasan Pelanggan. Konsep, Pengukuran, dan Strategi. Yogyakarta: ANDI.

Tjiptono Fandy, G. (2016). Service, Quality dan Satisfaction Edisi 4. Yogyakarta: ANDI.

Wulandari. (2017). Pengaruh Kualitas Pelayanan Kefarmasian Terhadap Kepuasan Pasien di Rumah Sakit Paru Dungus Madiun. Skripsi Wulandari.

Yunevy dan Haksamana. (2013). Analisis Kepuasan Berdasarkan Persepsi dan Harapan Pasien di Puskesmas Medokan Ayu Surabaya. Jurnal Administrasi Indonesia Volume 1. Yuniar. (2016). Kepuasan Pasien Peserta Program Jaminan Kesehatan Nasional terhadap Pelayanan 
Pengaruh Kualitas Pelayanan Kefarmasian

Kefarmasian di Apotek. Jurnal

Kefarmasian Indonesia, 39-48 

